\title{
Cumulative Radiation Dose and Cancer Risk Estimation in Common Diagnostic Radiology Procedures
}

\author{
Safoora Nikzad, ${ }^{1,}{ }^{*}$ Maryam Pourkaveh, ${ }^{2}$ Naghi Jabbari Vesal,, and Farideh Gharekhanloo ${ }^{3}$ \\ ${ }^{1}$ Department of Medical Physics, Faculty of Medicine, Hamadan University of Medical Sciences, Hamadan, Iran \\ ${ }^{2}$ Department of Radiology, Faculty of Paramedicine, Hamadan University of Medical Sciences, Hamadan, Iran \\ ${ }^{3}$ Department of Radiology, Faculty of Medicine, Hamadan University of Medical Sciences, Hamadan, Iran \\ "Corresponding author: Dr. Safoora Nikzad, Department of Medical Physics, Faculty of Medicine, Hamadan University of Medical Sciences, Hamadan, Iran. Tel: +98-8138380572, \\ Fax: +98-8138380208, E-mail: s.nikzad@umsha.ac.ir
}

Received 2017 August 27; Revised 2018 January 18; Accepted 2018 January 23.

\begin{abstract}
Background: Diagnostic radiology by the use of ionizing radiation plays a main contribution in the collective dose of human population. Knowing the radiation dose received by patients during a radiological examination is essential to prevent the excess health risk of exposure.

Objectives: The aim of this study was to estimate the collective dose and calculate the cancer risk probability due to common radiological procedures in four radiology imaging centers of Iran.

Patients and Methods: Four hundred seventy patients who underwent different radiological examinations including the skull, chest, abdomen, pelvis, lumbar, cervical and thoracic regions in four radiology centers of Hamadan, Iran were studied. The patients' entrance surface dose (ESD) was measured, and eventually, the effective dose (ED) was calculated. These parameters were compared with the reported values and international standard levels. Finally, the risk of cancer was determined by two different methods proposed in international commission on radiological protection (ICRP) 103.

Results: Mean values of ESD for chest, abdomen, pelvis, lumbar region, skull, cervical and thoracic regions were $0.43 \pm 0.09,2.51$ $\pm 0.19,2.47 \pm 0.02,3.21 \pm 0.17,2.15 \pm 0.11,1.35 \pm 0.15$, and $2.51 \pm 0.19 \mathrm{mGy}$, respectively. The mean values of ED were $0.05,0.33,0.25$, $0.42,0.02,0.05$ and $0.24 \mathrm{mSv}$, respectively for these organs. The cancer risk probability as a function of cumulative dose was 0.20 , $1.21,0.08,1.32,0.01,0.01$ and 0.04 (person $-\mathrm{Sv} \times 5 \%$ per Sievert) for the interested organs, respectively. The risk of cancer as a function of age and sex for male patients was $0.86,1.47,0.59,0.02,0.16,1.96$ and 0.76 (in 103 person) for the bladder, colon, liver, thyroid, esophagus, lung and stomach, respectively. These values were, 0.34 (or 2.12), 0.73 (or 4.47), 0.98, 0.43, 0.72, 0.19, $0.25,0.26$ and 1.20 (in 103 persons) for breast, lung, bladder, ovary, colon, liver, thyroid, esophagus and stomach for females.

Conclusion: Results show that the estimated health risk based on ICRP health risk of 500 cases per 10000 person -Sv ( $5 \%$ per Sievert) was in total about 2 cases for seven examinations in 2016. Risks of cancer as a function of age and sex for male patients were higher for lung and colon cancers and for females, it was higher for breast and lung cancers.
\end{abstract}

Keywords: Diagnostic Radiology, Cumulative Dose, Entrance Surface Dose, Effective Dose, Cancer Risk Estimation

\section{Background}

Diagnostic radiology by the use of ionizing radiation plays a main contribution in the collective dose of human population $(1,2)$. Knowing the radiation dose received by the patients during radiologic examination is essential in preventing the excess health risk of exposure (3).

Different parameters are used to determine the effects of radiation and to estimate the risk of cancer (3). The entrance skin dose (ESD) is the main parameter which determines the patient's dose in diagnostic radiology $(3,4)$. This parameter is defined as the absorbed dose in air at the point of intersection of the beam axis with the entrance surface of the patient (5). ESD can be measured using ion- ization chambers (IC) by the measurement of air kerma and also thermo luminescent dosimeters (TLD) easily fixed directly on the patient's skin $(5,6)$.

The next useful parameter is the effective dose (ED), which is affected by patient body structure and the radiological method. Calculation of this quantity is important to provide effective protection to the patients $(3,4,7,8)$. To calculate the ED, the ESD for each group of patients is used as the input parameter (9) and allowed to calculate ED by the use of constant coefficients reported in the reference tables of ICRP publication report (10).

It is important to know about these values in common radiological procedures. First, to compare the level of 
dose delivered to patients in each radiographic examination at a center with the national and international standards, Second, to calculate the average cumulative dose to the population and ultimately, to estimate the health risk arising from these radiations using risk models developed by international commission on radiological protection (ICRP) $103(7,11)$. It should be noted that these models are mainly based on incidence information from the life span study of Japanese atomic bomb survivor follow - up from 1958 to 1998 (11).

Although the effects of low dose radiations used in diagnostic procedures are stochastic and quite hard to determine, it is important to investigate these effects due to a large number of people enrolled in radiology procedures (12).

\section{Objectives}

The aim of this study was to calculate the excess risk of radiation in radiological procedures by the use of ICRP 103 proposed models. In this regard, first, the ESD of the patients was measured, in the following, the ED was calculated by the use of mean value of ESD and related constant coefficients proposed in the ICRP protocol (10). Afterward, these parameters were compared with the reported values in other studies and international standard levels. Eventually, the cancer risk was determined by two different methods proposed in ICRP103 (11)

\section{Patients and Methods}

\subsection{Collection of Data}

Data were collected from 473 patients who underwent imaging by different radiographic procedures including the chest, abdomen, pelvis, lumbar region, skull, cervical and thoracic regions in four hospitals led by Hamadan University of Medical Science, Iran. The radiological centers were Besat, Shahid Behesti, Sina and Farshchian Hospital. Patients' information including sex, age, weight, length and radiology technical parameters were also recorded. The possible contributing factors affecting the results of this study were errors in TLDs due to multiple readings, out of calibration, inaccuracies in placement on the patient's body or differences in imaging systems and their settings. It should be noted that the results of comparison of various imaging devices used in this study have already been reported in the previous study conducted by this research team (13).

\subsection{TLD Dosimeter}

Initially, lithium fluoride (LiF: Mg, TL) TLDs (traditional model of GR - 200) were annealed and calibrated with Cs -
137 source and read using the TLD reader (model 7103, Iran) $(13,14)$.

To measure the ESD, the consent form, confirmed by the Ethics Committee on Research, was completed and signed by the patients. Three TLDs were used for each patient. According to Sina et al., for low doses of radiation utilized in radiology procedures, the GR-200 TLDs have better sensitivity compared to TLD-100 (14).

\subsection{ESD and ED Measurements}

TLDs were put on the skin of patient where the $\mathrm{x}$-ray enters the body, on the medial of the field of exposure. Three TLDs were used for each patient, and their mean output was reported as the ESD of each patient in the exposure procedure $(3,7)$. Mean ESD for each organ of interest as well as the related constant coefficient were used to determine the ED parameter. ESD and ED measurement method were explained completely in a study performed by this team (13).

\subsection{Data Analysis}

The data were calculated and analyzed using SPSS 14 software (SPSS, Chicago, USA). The mean ESD calculated in each radiographic procedure was compared with the same values reported in national and international studies and also the standard level.

After measuring the ESD, the ED calculated using the conversion coefficients were determined by Monte Carlo procedures (15-17).

\subsection{Cancer Risk Probability Calculations}

To estimate the cancer risk, two procedures that were introduced by ICRP103 were used $(7,11)$. The first method is based on the collective effective dose. To estimate the collective effective dose, the average number of individuals exposed commonly per day was determined. To calculate the cancer risk probability, the ICRP103 proposed Equation 1 is as follows (7):

Cancer Risk Probability $=0.05 \times$ Collective Effective Dose

The other radiation risk models developed by ICRP 103 were Excess Relative Risk (ERR) and Excess Absolute Risk (EAR) models. These models were developed for cancer incidence and mortality as a function of sex and age at the time of exposure. For solid cancers, these models involve a linear dose response, allowing the modification of sex and age as follows:

$$
\mathrm{ERR}=\beta_{\mathrm{s}} \mathrm{D} \cdot \exp \left[\gamma(e-30)+\eta \log \left(\frac{a}{70}\right)\right]
$$

Where $\beta$ s ( $\beta$ Male or $\beta$ Female) is the sex specific estimates of ERR per Sv, D is the mean organ dose (Sv), e is age at the time of exposure in years and $\mathrm{a}$ is considered as the attained age (years). $\gamma$ and $\eta$ are constants that are given in ICRP 103 tables. Specific risk coefficients from Table 1 of Wall et al. (11) were used. 


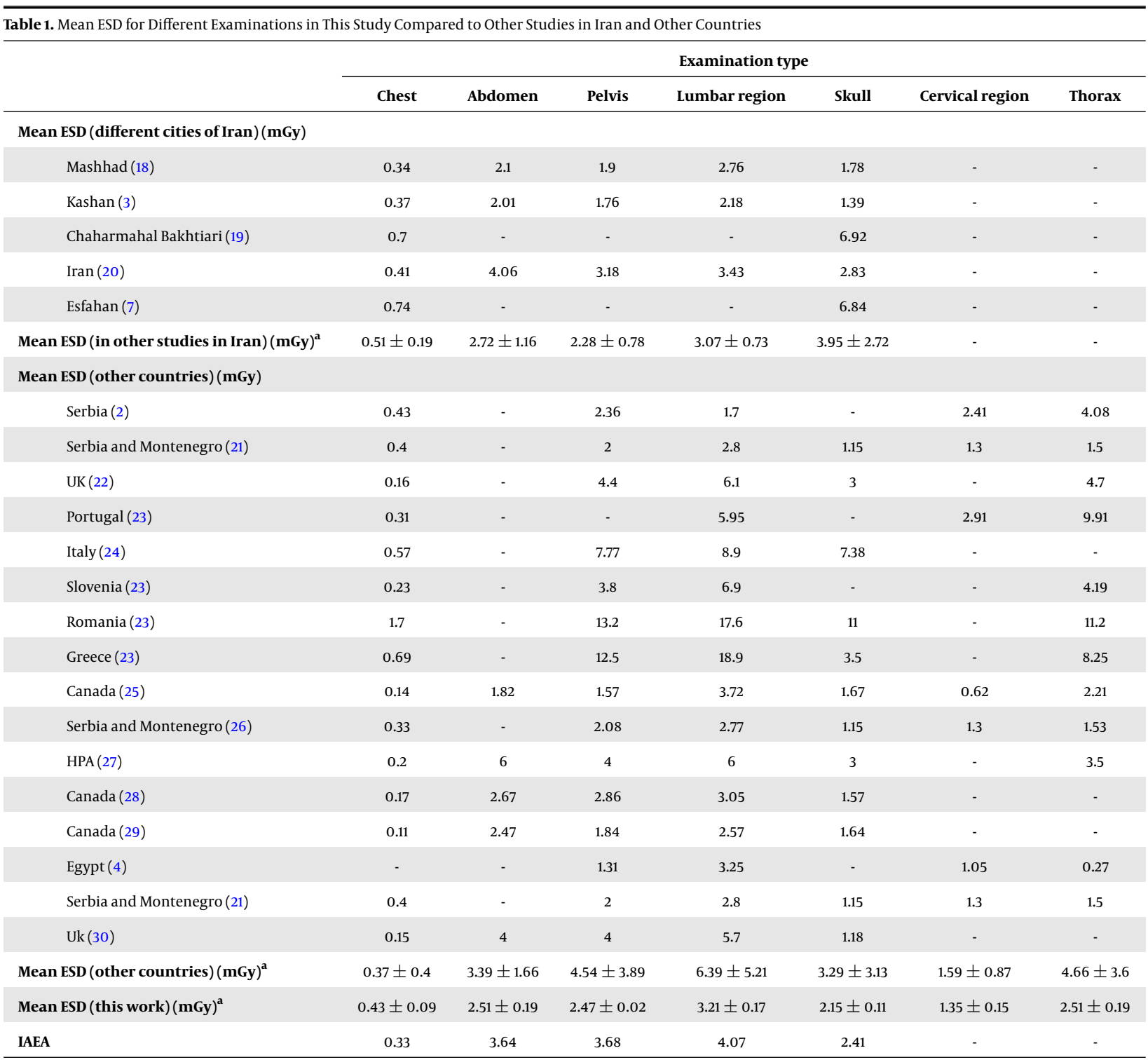

Abbreviations: ESD, entrance skin dose; IAEA, international atomic energy agency (IAEA); SD, standard deviation.

${ }^{\mathrm{a}}$ Values are expressed as mean $\pm \mathrm{SD}$.

\section{Results}

Patients characteristics such as age, weight and length as well as the $\mathrm{x}$ - ray machine parameters such as mean tube voltage, current and exposure time, field size and projection posture (anterior - posterior or lateral), field size and focus - detector distance (FDD) are presented in Table 2.

Tables 1 and 3 illustrate the values of the measured ESD and calculated ED, respectively, for each examination in this work with comparison to other studies in Iran and various countries.

Table 4 shows the total number of examinations for each test type per year as well as cumulative effective dose and excess cancer risk calculated by Equation 1 .

To determine the total lifetime cancer risks for radiology examination as a function of age and sex of the patients, the organ coefficients are determined for specific organs (breast, lung, bladder, colon, liver, thyroid, esophagus and stomach) depending on the age of patients, and the organ doses are determined for examination type (chest, abdomen, pelvic, lumbar region, skull, cervical, and thoracic regions). There is trouble choosing the constant coefficients of organs. For example, the dose of the chest as well as the thoracic region can be used for breast and lung. Therefore, for some patients, both organ doses were used. 


\begin{tabular}{|c|c|c|c|c|c|c|c|c|c|c|c|c|c|}
\hline \multirow{2}{*}{$\begin{array}{l}\text { Examination } \\
\text { type }\end{array}$} & \multirow{2}{*}{$\begin{array}{c}\text { Projection } \\
\text { posture }\end{array}$} & \multirow{2}{*}{$\begin{array}{l}\text { Tube } \\
\text { volt- } \\
\text { age } \\
\text { (kvp) }\end{array}$} & \multirow{2}{*}{$\begin{array}{l}\text { Tube } \\
\text { cur- } \\
\text { rent } \\
(\mathrm{mAs})\end{array}$} & \multirow{2}{*}{$\begin{array}{c}\text { Field } \\
\text { size }\end{array}$} & \multirow[t]{2}{*}{ FDD } & \multicolumn{2}{|c|}{ Number of patients } & \multicolumn{2}{|c|}{ Mean weight } & \multicolumn{2}{|c|}{ Mean length } & \multicolumn{2}{|c|}{ Age range } \\
\hline & & & & & & Male & Female & Male & Female & Male & Female & Male & Female \\
\hline Chest & AP & $65-75$ & $15-25$ & $\begin{array}{c}35 \times \\
35\end{array}$ & $\begin{array}{c}150- \\
165\end{array}$ & 38 & 32 & 79 & 65 & 178 & 163 & $16-71$ & $20-75$ \\
\hline Abdomen & AP & $65-75$ & $20-30$ & $\begin{array}{c}14 \times \\
17\end{array}$ & $\begin{array}{c}105- \\
120\end{array}$ & 35 & 34 & 71 & 59 & 175 & 159 & $24-76$ & $25-70$ \\
\hline Pelvis & $\mathrm{AP}$ & $65-75$ & $15-25$ & $\begin{array}{c}24 \times \\
30\end{array}$ & $\begin{array}{c}70- \\
90 \\
\end{array}$ & 30 & 38 & 84 & 66 & 184 & 160 & $20-73$ & $18-79$ \\
\hline $\begin{array}{l}\text { Lumbar } \\
\text { region }\end{array}$ & $\mathrm{AP}$ & $65-85$ & $15-40$ & $\begin{array}{c}14 \times \\
17\end{array}$ & $65-95$ & 38 & 31 & 81 & 71 & 185 & 166 & $31-69$ & $19-81$ \\
\hline Skull & AP & $\begin{array}{c}60- \\
70\end{array}$ & $15-35$ & $\begin{array}{c}24 \times \\
30\end{array}$ & $\begin{array}{l}70- \\
90\end{array}$ & 37 & 31 & 76 & 63 & 179 & 158 & $17-66$ & $21-59$ \\
\hline $\begin{array}{l}\text { Cervical } \\
\text { region }\end{array}$ & AP & $70-80$ & $10-40$ & $\begin{array}{c}24 \times \\
30\end{array}$ & $\begin{array}{l}105- \\
120\end{array}$ & 28 & 32 & 77 & 76 & 177 & 165 & $32-75$ & $29-65$ \\
\hline Thorax & $\mathrm{AP}$ & $70-75$ & $25-90$ & $\begin{array}{c}30 \times \\
40\end{array}$ & $\begin{array}{c}100- \\
110\end{array}$ & 34 & 35 & 88 & 58 & 181 & 168 & $40-76$ & $46-71$ \\
\hline
\end{tabular}

Abbreviations: AP, anterior - posterior; FDD, focus - detector distance.

\begin{tabular}{|c|c|c|c|c|c|c|c|}
\hline Examination type & Chest & Abdomen & Pelvis & $\begin{array}{c}\text { Lumbar } \\
\text { region }\end{array}$ & Skull & $\begin{array}{c}\text { Cervical } \\
\text { region }\end{array}$ & Thorax \\
\hline \multicolumn{8}{|l|}{ Mean ED (other studies) (msv) } \\
\hline Serbia (2) & 0.03 & - & 0.35 & 0.24 & - & 0.09 & 1.75 \\
\hline Kashan (3) & 0.04 & 0.28 & 0.28 & 0.23 & 0.01 & - & - \\
\hline Egypt (4) & - & - & 0.09 & 0.41 & - & 0.05 & 0.02 \\
\hline UK E - 103 (11) & 0.01 & 0.43 & 0.28 & 0.39 & 0.02 & - & - \\
\hline Esfahan (7) & 0.11 & - & - & - & 0.07 & - & - \\
\hline Canada (25) & 0.02 & 0.14 & 0.16 & 0.38 & 0.02 & 0.02 & 0.22 \\
\hline Canada (28) & 0.04 & - & 0.29 & 0.28 & 0.01 & 0.06 & 0.14 \\
\hline Serbia and Montenegro (26) & 0.02 & 0.7 & 0.7 & 0.7 & - & - & 0.4 \\
\hline Uk E-60 (30) & 0.01 & 0.47 & 0.45 & 0.41 & 0.02 & - & - \\
\hline Mean ED (other countries) & $0.03 \pm 0.03$ & $0.40 \pm 0.21$ & $0.32 \pm 0.18$ & $0.38 \pm 0.15$ & $0.02 \pm 0.02$ & $0.05 \pm 0.03$ & $0.5 \pm 0.71$ \\
\hline Mean ED (this work) (msv) & 0.05 & 0.33 & 0.25 & 0.42 & 0.02 & 0.05 & 0.24 \\
\hline IAEA & 0.05 & 0.8 & 1 & 1.2 & - & - & - \\
\hline
\end{tabular}

Abbreviations: ED, effective dose; IAEA, international atomic energy agency (IAEA).

The results are shown in Tables 5 and 6 for male and female patients as follows.

\section{Discussion}

The results of this study showed that the calculated ESD of different organs was greater than those reported in other studies in Iran including Kashan and Mashhad (3, 18). Nevertheless, these values were lesser than those reported in other parts of Iran, Chaharmahal and Bakhtiari (19), Shiraz (14), (20) and Esfahan (7). It should be noted that the mean ESD of different organs reported in all the other countries shows a wide range and reflects a large standard deviation. Compared to the other countries, the calculated ESDs in this study were greater than that reported in Canada (25), Serbia (26) and Serbia (28). The use of a suitable radiographic technique, with appropriate $x$ ray tube voltages and sufficient beam filtration is the probable reason for the low doses obtained in these countries in comparison with the others (21). Other affecting factors are different speed class of filmscreen and the manual exposure control settings used in different countries $(21,31)$. The results revealed that the mean chest ESD in this study is higher than the international atomic energy agency (IAEA) level, but for the other organs, the mean ESDs were lower than IAEA standards. 


\begin{tabular}{|c|c|c|c|c|}
\hline Examination type & ED/Exam (msv) & Number of examinations per year & Total collective dose (person - sv) & $\begin{array}{c}\text { Estimated cancer risk (person - } \mathrm{Sv} \times \mathbf{5} \% \\
\text { per sievert) }\end{array}$ \\
\hline Chest & 0.05 & 83545 & 4.18 & 0.20 \\
\hline Abdomen & 0.33 & 73215 & 24.16 & 1.21 \\
\hline Pelvis & 0.25 & 6276 & 1.57 & 0.08 \\
\hline Lumbar region & 0.42 & 63102 & 26.5 & 1.32 \\
\hline Skull & 0.02 & 11293 & 0.22 & 0.01 \\
\hline Cervical region & 0.05 & 5415 & 0.27 & 0.01 \\
\hline Thorax & 0.24 & 3212 & 0.77 & 0.04 \\
\hline Total & 1.36 & 246058 & 57.67 & 2.87 \\
\hline
\end{tabular}

Abbreviation: ED, effective dose; SV, sievert.

Table 5. Total Lifetime Cancer Risks for Radiology Examination as a Function of Age and Sex of Male Patients

\begin{tabular}{|c|c|c|c|c|c|}
\hline \multirow[t]{2}{*}{ Examination type } & \multirow[t]{2}{*}{ Mean organ dose (mGy) } & \multirow[t]{2}{*}{ Mean age } & \multicolumn{2}{|c|}{ Organ age and sex specific risk coefficient } & \multirow{2}{*}{$\begin{array}{l}\text { Lifetime cancer risks (in } \\
\qquad 10^{3} \text { person) }\end{array}$} \\
\hline & & & Organ & Coefficients (per Gy) & \\
\hline \multirow{2}{*}{ Chest } & \multirow{2}{*}{0.5} & \multirow{2}{*}{39} & Breast & - & - \\
\hline & & & Lung & 0.8 & 0.39 \\
\hline Abdomen & 2.47 & 51 & Bladder & 0.35 & 0.86 \\
\hline Pelvis & 2.45 & 40 & colon & 0.6 & 1.47 \\
\hline Lumbar region & 3.30 & 43 & liver & 0.18 & 0.59 \\
\hline Skull & 2.20 & 40 & Thyroid & 0.01 & 0.02 \\
\hline Cervical region & 1.37 & 45 & Esophagus & 0.12 & 0.16 \\
\hline \multirow{2}{*}{ Thorax } & \multirow{2}{*}{2.45} & \multirow{2}{*}{43} & lung & 0.8 & 1.96 \\
\hline & & & Stomach & 0.31 & 0.76 \\
\hline
\end{tabular}

Table 6. Total Lifetime Cancer Risks for Radiology Examination as a Function of Age and Sex of Female Patients

\begin{tabular}{|c|c|c|c|c|c|}
\hline \multirow[t]{2}{*}{ Examination type } & \multirow[t]{2}{*}{ Mean organ dose (mGy) } & \multirow[t]{2}{*}{ Mean age } & \multicolumn{2}{|c|}{ Organ age and sex specific risk coefficient } & \multirow{2}{*}{$\begin{array}{l}\text { Lifetime cancer risks (in } \\
10^{3} \text { person) }\end{array}$} \\
\hline & & & Organ & Coefficients (per Gy) & \\
\hline \multirow{2}{*}{ Chest } & \multirow{2}{*}{0.41} & \multirow{2}{*}{47} & Breast & 0.84 & 0.34 \\
\hline & & & Lung & 1.78 & 0.73 \\
\hline \multirow{2}{*}{ Abdomen } & \multirow{2}{*}{2.53} & \multirow{2}{*}{48} & Bladder & 0.39 & 0.98 \\
\hline & & & Ovary & 0.17 & 0.43 \\
\hline Pelvis & 2.48 & 42 & Colon & 0.29 & 0.72 \\
\hline Lumbar region & 3.22 & 50 & Liver & 0.06 & 0.19 \\
\hline Skull & 1.96 & 38 & Thyroid & 0.13 & 0.25 \\
\hline Cervical region & 1.26 & 50 & Esophagus & 0.21 & 0.26 \\
\hline \multirow{3}{*}{ Thorax } & \multirow{3}{*}{2.51} & \multirow{3}{*}{49} & Breast & 0.84 & 2.12 \\
\hline & & & Lung & 1.78 & 4.47 \\
\hline & & & Stomach & 0.48 & 1.20 \\
\hline
\end{tabular}

Table 3 shows that the ED in this study was greater than that in other studies for the chest and lumbar region. This amount is in agreement with the IAEA standard level for the chest and other organs, the ED in this study was lower than the mean ED from IAEA level.

The next aim of this study was to estimate the extent of risk on the basis of the EDs calculated for different organs and the annual number of diagnostic $\mathrm{x}$ - rays undertaken in Hamadan.

Table 4 presents the estimated health risk based on ICRP health risk of 500 cases per 10000 person - Sv (5\% per sievert). The results show that the annual total collective dose received by the population in four hospitals in Hamadan in 2016 was 57.67 person - Sv. In a study carried 
out by Baradaran et al. (7), it was estimated that in seven hospitals in Isfahan, two cases of health risk (40.18 person - Sv 5 \% per sievert) may be attributable to diagnostic X rays due to the chest lateral (LAT) examination and one case (22.30 person - Sv) for chest posterior - anterior (PA) projection which is in total about three cases for chest and skull examinations in year 2011. The results of this project show that one case of health risk (24.16 person - Sv $5 \%$ per sievert) may in the future be attributable to diagnostic $X$ rays due to the abdomen PA examination and one case (26.5 person - Sv) for lumbar PA projection which is in total about two cases for seven examinations in year 2016. Therefore, the risk of cancer due to diagnostic radiology is lower in Hamadan than Isfahan, which is due to the lesser number of patients in Hamadan using radiology examinations. In UK, $0.6 \%$ and in the other 13 countries, the range of 0.6 to $1.8 \%$ and in Japan, $3 \%$ of the cumulative risk of cancer could be related to diagnostic radiology (31).

Estimating the risk of cancer as a function of age and sex by the ICRP 103 proposed procedures showed that for male patients, the risk of lung and colon cancer due to the absorbed dose from thoracic and pelvic radiological examinations is higher than the others. For female patients, the risks of breast and lung cancer due to thoracic radiology procedures are the highest risk organs. Although thyroid is a radiosensitive organ, the results of this study show that the risk of thyroid cancer is lower than the others. The reference health protection agency (HPA) investigations show that the agreement between the risk estimation and ICRP values is not good for cancers of the red bone marrow and thyroid (11). It seems there is an agreement between the results of this study and the HPA investigations about the risk of thyroid cancer.

\section{Acknowledgments}

The authors would like to thank Besat, Shahid Behesti, Sina and Farshchian Hospitals of Hamadan University of Medical Sciences, for their critical comments and technical advices.

\section{Footnotes}

Authors' Contributions: None declared.

Financial Disclosure: None declared.

Funding/Support: None declared.

\section{References}

1. Gron P, Olerud HM, Einarsson G, Leitz W, Servomaa A, Schoultz BW, et al. A Nordic survey of patient doses in diagnostic radiology. Eur Radiol. 2000;10(12):1988-92. doi: 10.1007/s003300000535. [PubMed: 11305583].
2. Ciraj-Bjelac O, Markovic S, Kosutic D. Patient dosimetry in diagnostic radiology. Nucl Tech Radiat Protect. 2003;18(1):36-41. doi: 10.2298/ntrp0301036c.

3. Aliasgharzadeh A, Mihandoost E, Masoumbeigi M, Salimian M, Mohseni M. Measurement of Entrance Skin Dose and Calculation of Effective Dose for Common Diagnostic X-Ray Examinations in Kashan, Iran. Glob J Health Sci. 2015;7(5):202-7. doi: 10.5539/gjhs.v7n5p202. [PubMed: 26156930]. [PubMed Central: PMC4803878].

4. Ofori K, Gordon SW, Akrobortu E, Ampene AA, Darko EO. Estimation of adult patient doses for selected X-ray diagnostic examinations. $J \mathrm{Ra}$ diat Res Appl Sci. 2014;7(4):459-62. doi:10.1016/j.jrras.2014.08.003.

5. Noel A. Patient Dose in Diagnostic Radiology. Phys Med Imag Applic. 2007:397-404. doi: 10.1007/978-1-4020-5653-6 31.

6. Sharifat I, Oyeleke O. Patient entrance skin doses at Minna and Ibadan for common diagnostic radiological examinations. Bayero J Pure Appl Sci. 2009;2(1):1-5.

7. Shahbazi-Gahrouei D, Baradaran-Ghahfarokhi M. Assessment of entrance surface dose and health risk from common radiology examinations in Iran. Radiat Prot Dosimetry. 2013;154(3):308-13. doi: 10.1093/rpd/ncs244. [PubMed: 22977172].

8. Neta G, Rajaraman P, Berrington de Gonzalez A, Doody MM, Alexander $\mathrm{BH}$, Preston $\mathrm{D}$, et al. A prospective study of medical diagnostic radiography and risk of thyroid cancer. Am J Epidemiol. 2013;177(8):8009. doi: 10.1093/aje/kws315. [PubMed: 23529772]. [PubMed Central: PMC3668423].

9. Jones DG, Wall BF. Normalized organ doses for medical X-ray examinations calculated using Monte Carlo techniques. Chilton, UK; 1994. Contract No.: NRPBSR262.

10. International Commission on Radiological Protection. Compendium of dose coefficients based on ICRP Publication 60. ICRP Publication 119. Ann. ICRP. 2012;41(1).

11. Wall BF, Haylock R, Jansen JTM, Hillier MC, Hart D, Shrimpton PC. Radiation risks from medical X-ray examinations as a function of the age and sex of the patient. Chilton, Didcot Oxfordshire: Health Protection Agency, Centre for Radiation, Chemical and Environmental Hazards 2011.

12. Hall EJ, Brenner DJ. Cancer risks from diagnostic radiology. BrJ Radiol. 2008;81(965):362-78. doi: 10.1259/bjr/01948454. [PubMed: 18440940].

13. Pourkaveh M, Nikzad S. Measuring the Entrance Surface Dose and Effective Dose for Chest and Abdomen X-ray Examinations in Hamedan, Iran and their Comparison with International Standards. J Mazandaran Univ Med Sci. 2017;27(147):249-58.

14. Sina S, Zeinali B, Karimipoorfard M, Lotfalizadeh F, Sadeghi M, Zamani $\mathrm{E}$, et al. Investigation of the entrance surface dose and dose to different organs in lumbar spine imaging. J Biomed Phys Eng. 2014;4(4):11926. [PubMed: 25599058]. [PubMed Central: PMC4289519].

15. Hart D, Jones DG, Wall BF. Coefficients for estimating effective doses from paediatric X-ray examinations. Oxon: National Radiological Protection Board;1996. Contract No.: NRPB-R279.

16. Hart D, Jones DG, Wall BF. Estimation of effective dose in diagnostic radiology from entrance surface dose and dose-area product measurements. National Radiological Protection Board; 1994. Contract No.: NRPBR262.

17. Ginsberg GM, Schlesinger T, Ben-Shlomo A, Kushilevsky A, Margaliot $\mathrm{M}$, Oren $\mathrm{M}$, et al. An economic evaluation of the use of rare earth screens to reduce the radiation dose from diagnostic X-ray procedures in Israel. Br J Radiol. 1998;71(844):406-12. doi: 10.1259/bjr.71.844.9659134. [PubMed: 9659134].

18. Bahreyni Toossi MT, Malekzadeh M. Radiation dose to newborns in neonatal intensive care units. Iran J Radiol. 2012;9(3):145-9. doi: 10.5812/iranjradiol.8065. [PubMed: 23329980]. [PubMed Central: PMC3522370].

19. Shahbazi-Gahrouei D. Entrance surface dose measurements for routine X-ray examinations in Chaharmahal and Bakhtiari hospitals. Iranian J Radiat Res. 2006;4(1):29-34

20. Asadinezhad M, Bahreyni Toossi MT. Doses to patients in some routine diagnostic X-ray examinations in Iran: proposed the first Iranian diagnostic reference levels. Radiat Prot Dosimetry. 2008;132(4):409-14. doi: 10.1093/rpd/ncn308. [PubMed: 19106177]. 
21. Ciraj O, Markovic S, Kosutic D. Patient dose from conventional diagnostic radiology procedures in Serbia and Montenegro. J Prev Med. 2004;12(3-4):26-34.

22. Shrimpton PC, Wall BF, Jones DG, Fisher ES, Hillier MC, Kendall GM, et al. Doses to patients from routine diagnostic X-ray examinations in England. Br J Radiol.1986;59(704):749-58. doi: 10.1259/0007-1285-59704-749. [PubMed: 3730774].

23. United Nations Scientific Committee on the Effects of Atomic Radiation:Source and Effects of Ionizing Radiation . Report to the General Assembly. New York: United Nations; 2000.

24. Padovani R, Contento G, Fabretto M, Malisan MR, Barbina V, Gozzi G. Patient doses and risks from diagnostic radiology in North-east Italy. BrJ Radiol.1987;60(710):155-65. doi:10.1259/0007-1285-60-710-155. [PubMed: 3815011].

25. Osei EK, Darko J. A survey of organ equivalent and effective doses from diagnostic radiology procedures. ISRN Radiol. 2013;2013:204346. doi: 10.5402/2013/204346. [PubMed: 24977137]. [PubMed Central: PMC4045519].

26. Ciraj O, Markovic S, Kosutic D. First results on patient dose mea- surements from conventional diagnostic radiology procedures in Serbia and Montenegro. Radiat Prot Dosimetry. 2005;113(3):330-5. doi: 10.1093/rpd/nch469. [PubMed: 15755772].

27. Health Protection Agency. HPA Recommended national reference doses for individual radiographs on adult patients. Centre for Radiation, Chemical and Environmental Hazards; 2000.

28. Compagnone G, Pagan L, Bergamini C. Local diagnostic reference levels in standard X-ray examinations. Radiat Prot Dosimetry. 2005;113(1):54-63. doi: 10.1093/rpd/nch432. [PubMed: 15572400].

29. Compagnone G, Pagan L, Baleni MC, Calzolaio FL, Barozzi L, Bergamini C. Patient dose in digital projection radiography. Radiat Prot Dosimetry. 2008;129(1-3):135-7. doi: 10.1093/rpd/ncn013. [PubMed: 18252850].

30. Hart D, Hillier MC, Shrimpton PC. Doses to patients from radiographic and Fluoroscopic X-ray imaging procedures in the UK-2010 Review. Health Protection Agency, Centre for Radiation, Chemical and Environmental Hazards; 2010. Contract No.: HPA-CRCE-034.

31. de Gonzalez AB, Darby S. Risk of cancer from diagnostic X-rays: estimates for the UK and 14 other countries. Lancet. 2004;363(9406):34551. 